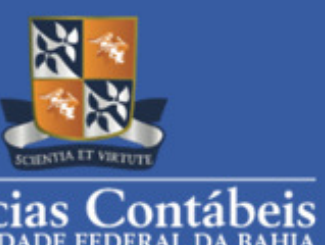

DOI: http://dx.doi.org/10.9771/rc-ufba.v14i3.36049

\title{
HOLDING E OS PROCESSOS DE SUCESSÃO FAMILIAR E DE PLANEJAMENTO TRIBUTÁRIO NO SEGMENTO DE CAFEICULTURA
}

\author{
HOLDING AND FAMILY SUCCESSION AND TAX PLANNING PROCESSES IN THE \\ COFFEE SEGMENT
}

\author{
Charles Silva Rocha ${ }^{1}$ \\ Centro Universitário de Patos de Minas \\ charles_silvarocha@yahoo.com.br
}

\author{
Geovane Camilo dos Santos \\ Universidade Federal de Uberlândia \\ geovane_camilo@yahoo.com.br
}

\section{Dryelle Laiana de Jesus Silva dos Santos \\ Universidade Federal de Uberlândia dryellelayana@gmail.com}

\begin{abstract}
RESUMO
O agronegócio é considerado o motor da economia brasileira, seja pela sua participação no Produto Interno Bruto (PIB), seja pela geração de emprego e renda. Especificamente, um dos setores com destaque é a cafeicultura, o qual tem característica predominantemente familiar. Contudo, no agronegócio, a sucessão diretiva devido à falta de planejamento adequado é um problema que pode colocar em risco a continuidade do negócio, além de onerar os aspectos tributários. Estudos que analisem o processo de sucessão familiar e o impacto do planejamento tributário mediante o uso de holding ainda são carentes no Brasil. Em razão disso, esta pesquisa vem preencher essa lacuna, visto que este trabalho verifica a viabilidade da utilização de uma empresa holding para facilitar o processo sucessório e a obtenção de elisão fiscal em um grupo de cafeicultores mineiros. Os dados foram coletados das projeções orçamentárias cedidas pelos empreendedores, de 2016 a 2022. As análises revelaram que a holding pode ser útil ao planejamento sucessório, pois separa as relações pessoais familiares das profissionais. Sob a ótica tributária, o melhor regime é pessoa física tributada com base no livro caixa conforme carga tributária efetiva.
\end{abstract}

Palavras-chave: Empresa familiar. Holding. Planejamento sucessório e tributário.

\section{ABSTRACT}

Agribusiness is considered the engine of the Brazilian economy, whether due to its participation in the Gross Domestic Product (GDP), and for the generation of jobs and income. Specifically, one of the highlighted sectors is coffee farming which has predominantly family characteristic.

${ }^{1}$ Rua Alfredo Alves Barcelos, 31 Apto 301 - Centro em Patos de Minas - MG, CEP: 38.700 - 040 
However, in agribusiness the directive succession due to the lack of adequate planning it is a problem that can put at risk the business continuity, in addition to burden the tax aspects. Studies that analyze the family succession process and the impact of tax planning using a holding company are still lacking in Brazil. Because of this, this research comes to fill this gap, since this work verifies the feasibility of using a holding company to facilitate the succession process and to obtain tax avoidance in a group of coffee farmers in Minas Gerais. The data were collected from the budget projections provided by the entrepreneurs, from 2016 to 2022. The analyzes revealed that the holding Company can be useful for succession planning, as it separates family personal relationships from professionals. Under the tax perspective the best regime is individuals taxed based on the cash book according effective tax burden.

Keywords: Family business. Holding. Inheritance and tax planning.

\section{INTRODUÇÃO}

Diante da crescente industrialização ocorrida nas duas últimas décadas (LAMONICA; FEIJÓ, 20110), o agronegócio continua como um dos principais motores da economia brasileira (CONFEDERAÇÃO DA AGRICULTURA E PECUÁRIA DO BRASIL [CNA], 2020). Os resultados positivos são fruto do aumento da demanda por alimentos provocado pelo crescimento populacional das cidades em todo o mundo. Entre os papéis do agronegócio, destacam-se a produção de alimentos com qualidade e baixo custo, o abastecimento da indústria de matérias-primas, as melhores condições de vida dos trabalhadores rurais, o provimento de recursos financeiros ao país e o equilíbrio da balança comercial (ARAÚJO, 2013).

Diante desse cenário, ressalta-se a importância da Cafeicultura no agronegócio brasileiro. O café é de origem africana e está presente no Brasil desde o Século XVIII, sendo os estados de Minas Gerais, Espírito Santo, São Paulo e Bahia os maiores produtores do grão (GIORDANO; REZENDE, 2010). Conforme dados do Conselho dos Exportadores de Café do Brasil (COCAFÉ), as exportações brasileiras de café alcançaram 34 milhões de sacas, com uma receita de 5,39 bilhões de dólares no ano de 2015. Destaca-se que o Brasil é o maior exportador de café do mundo, com uma participação no mercado mundial de $71 \%$, sendo os Estados Unidos o principal destino (COCAFÉ, 2016).

Tão importante quanto os resultados do agronegócio brasileiro são os empreendedores e empreendimentos agropecuários, afinal, são eles que viabilizam a produção agrícola do país. Um empreendimento agropecuário se caracteriza pela exploração econômica e racional da terra por pessoa física ou jurídica, de direito público ou privado, cujo objetivo é o de obter produção animal ou vegetal (CREPALDI, 2012). Em sua maioria, os empreendimentos agropecuários são familiares, sendo essa, aliás, a forma empresarial predominante em todo o mundo e, portanto, fundamental para a economia global (OLIVEIRA, 2006).

Nesse cenário, um sério problema que afeta as empresas familiares refere-se à sobrevivência após a sucessão diretiva desses empreendimentos (BERNHOEFT, 1996; LEONE, 2004; FREITAS; FREZZA, 2016). Atualmente, o dilema enfrentado reside no conservadorismo dos fundadores e dirigentes frente à necessidade imposta pela economia globalizada de realização de planejamento sucessório (PETRÓ; CASTRO, 2016). No entendimento de Mamede e Mamede (2017), há expectativa de que a sobrevivência póssucessão aumente na medida em que dirigentes mais preparados passem a adotar modernos modelos de governança. 
Em matéria tributária, as empresas agropecuárias familiares não se distinguem das demais empresas, pois estão igualmente sujeitas a várias normas, regulamentos e altas cargas tributárias. Segundo dados do Ministério da Fazenda (2018) relativos a 2017, 48,44\% da arrecadação do país vêm da tributação sobre a produção de bens e serviços. Diante do contexto apresentado, o planejamento tributário surge como alternativa que permite a reorganização das rotinas fiscais das empresas. Para Oliveira (2006), essa ferramenta auxilia na avaliação da atual posição da empresa, bem como permite simular cenários conforme o planejamento estratégico e a busca pela melhor alternativa tributária.

Uma alternativa adotada por empresas familiares como forma de solucionar várias das questões apontadas é a constituição de uma empresa do tipo holding. Segundo Silva e Rossi (2017), mediante a holding, um empresário pode consolidar seu patrimônio, desenvolver um planejamento sucessório, promover a reorganização tributária, intervindo em processos e rotinas fiscais, fortalecendo sua empresa e preparando-a para sobreviver aos desafios impostos pela globalização.

Diante dessa contextualização, o problema de pesquisa é: qual a viabilidade de constituição de uma holding para facilitar o processo sucessório familiar e o planejamento tributário em uma empresa agropecuária? Para responder ao referido problema, esta pesquisa tem como objetivo geral: identificar a viabilidade da utilização de uma holding para facilitar o processo de sucessão familiar e a redução da carga tributária para uma empresa agropecuária.

Este estudo se justifica quanto aos aspectos acadêmicos ao contribuir com pesquisas que apresentem as holdings como alternativas para auxiliar nos processos de sucessão e de planejamento tributário nas empresas agropecuárias familiares, não tendo sido, inclusive, identificadas muitas pesquisas ligadas a esse tema. $\mathrm{O}$ estudo também irá contribuir para a produção de informações que possam subsidiar os empreendedores rurais nas decisões pertinentes ao tema abordado.

\section{REFERENCIAL TEÓRICO}

Nesta seção, é discutido o referencial teórico desta pesquisa, abordando os seguintes tópicos: agricultura brasileira, cafeicultura no Brasil, empresas familiares, sucessão familiar e planejamento sucessório, carga tributária brasileira, planejamento tributário e empresa holding.

\subsection{AGRICULTURA BRASILEIRA}

O termo agricultura era, até recentemente, suficiente para qualificar toda a cadeia de produção agrícola do país, mas as transformações ocorridas no setor nos últimos anos fizeram com que o entendimento sobre o seu significado não coubesse mais dentro dos limites dessa palavra. A transferência de atividades antes realizadas dentro da propriedade rural para fora dela colocou a agricultura dentro de um sistema maior e mais complexo.

Em conformidade com Araújo (2013), para viabilizar a produção agropecuária, é necessário um sistema que sustente as relações entre diferentes profissionais e áreas de conhecimento, visto que, atualmente, o exercício da atividade não está limitado à atuação dos grupos tradicionais. $\mathrm{O}$ autor ressalta ainda que transformações também ocorreram fora das propriedades rurais, haja vista que diversas formações acadêmicas passaram a ser ofertadas àqueles que se interessam pelo setor, bem como foram introduzidos novos conceitos, sobretudo, o de "negócio".

Para sobreviver às mudanças impostas pela economia globalizada, as propriedades rurais deixaram de ser autossuficientes e tiveram que buscar recursos e informações fora da porteira, bem como se especializam, utilizam infraestrutura externa, adotam o uso de 
tecnologias modernas (máquinas, material biológico, serviços e softwares) e buscam uma visão de mercado com foco na produção de excedentes (ARAÚJO, 2013). Segundo Callado (2013), a complexidade da atual configuração econômica e social exige que o agronegócio seja tratado sob a perspectiva da abordagem sistêmica, ou seja, como parte de um complexo emaranhado de relações interdependentes.

Tradicionalmente, as atividades econômicas são agrupadas em setores identificados como: primário, que realiza a produção de itens in natura; secundário, cujo objetivo é realizar o processamento e a transformação dos itens primários em bens de consumo; e terciário, que se ocupa da prestação de serviços. A atividade agrícola, ainda sob a denominação de agricultura ou agropecuária, estava inserida no setor primário, porém a mudança de paradigma e o reconhecimento da complexidade que envolve a produção agrícola fizeram surgir o conceito de agronegócio. Para Bacha (2012), há mudanças, inclusive, no posicionamento dos governos que, no caso do Brasil, até a década de 80, contava com o Ministério da Agricultura, o qual, a partir de então, passou a se chamar Ministério da Agricultura, Pecuária e Abastecimento (MAPA), reconhecendo-se o conceito de cadeia produtiva.

\subsection{CAFEICULTURA NO BRASIL}

A cafeicultura no Brasil, oriunda da Etiópia, teve início em meados do Século XVIII, tendo o café encontrado no país plenas condições para o seu desenvolvimento. Posto de lado, $a$ priori, em detrimento da produção de açúcar, o café alcançou a condição de principal produto da balança comercial brasileira durante o segundo império, marcando um período conhecido como o renascimento agrícola colonial (DANTAS; SANTOS, 2009).

Atualmente, o café é cultivado em grande escala no Brasil, que é o maior produtor mundial do grão. Os estados com maiores produções são Minas Gerais, Espírito Santo, São Paulo e Bahia (COCAFÉ, 2016). No país, são produzidos cafés das variedades arábica e robusta, com predomínio da primeira, que corresponde a $87,5 \%$ de toda a produção nacional. Conforme dados apresentados pelo Cocafé (2016), as exportações brasileiras alcançaram 34 milhões de sacas, gerando uma receita de 5,39 bilhões de dólares. Ainda segundo o Cocafé (2016), os Estados Unidos é o principal destino do café brasileiro, respondendo por $19 \%$ dos embarques realizados, seguidos pela Alemanha (18,3\%), Itália (8,5\%), Japão $(7,5 \%)$ e Bélgica $(6,1 \%)$.

Ainda segundo os dados do Cocafé (2016), as exportações brasileiras de café responderam por $11 \%$ do saldo positivo da balança comercial, respondendo o Brasil por $71 \%$ de todo o café exportado no mundo. Somam-se a isso projeções animadoras que indicam que, entre 2016 e 2030, o consumo mundial de café saltará de 150 milhões de sacas por ano para mais de 213 milhões de sacas.

\subsection{EMPRESAS FAMILIARES}

As empresas familiares são importantes, conforme palavras de Oliveira (2006), pois, na percepção do autor, elas representam, em todo o mundo, cerca de $70 \%$ dos empreendimentos. Essa visão é complementada por Leone (2005), ao afirmar que, mesmo em um momento no qual se destaca o poder econômico de empresas "S.A." por todo o mundo, as empresas familiares mantêm sua força e importância e, em países como Espanha, Inglaterra, Alemanha e Brasil, elas representam entre $70 \%$ e $90 \%$ das organizações empresariais existentes. Já nos Estados Unidos, elas respondem por mais de $60 \%$ dos postos de trabalho gerados e $64 \%$ do Produto Interno Bruto (PIB). No Brasil, segundo Larghi e Rossetto (2017), com base na 
Pesquisa de Empresas Familiares no Brasil divulgada pela PWC no final de 2016, as empresas familiares representavam $80 \%$ do total de companhias existentes e respondiam por $50 \%$ do PIB do país.

Uma das principais características da empresa familiar é a sucessão hereditária do poder decisório, porém Oliveira (2006) destaca outras características, como a valorização da confiança mútua, os comportamentos influenciados pela relação afetiva, a dedicação, a austeridade, a fidelidade, a ausência de separação entre os recursos da empresa e os do sócio. Em relação aos fatores que favorecem as empresas familiares, o autor menciona a obtenção de vantagem pela associação do nome da família à qualidade dos produtos e serviços comercializados e o fato de conseguirem suportar melhor os períodos de crise econômica por não sofrerem pressões de acionistas por melhores resultados.

Entretanto, os empreendimentos familiares apresentam vários problemas, tais como: concentração em um único produto ou serviço, o que pode atrelar o ciclo de vida da empresa ao ciclo de vida do produto ou serviço; falta de planejamento estratégico; desavenças originadas do processo sucessório; prevalência dos desejos individuais; ausência de clareza na definição do negócio; inexistência de processos bem-definidos; falta de recursos tecnológicos e humanos adequados; e, talvez, o mais prejudicial à sua sobrevivência é a falta de um planejamento sucessório (MAMEDE; MAMEDE, 2017). Dados estatísticos demonstram que apenas 30\% das empresas familiares conseguem sobreviver à primeira sucessão e que entre $10 \%$ e $15 \%$ dessas empresas chegam à terceira sucessão (LEONE, 2005).

\subsection{SUCESSÃO FAMILIAR E PLANEJAMENTO SUCESSÓRIO}

O Direito Sucessório, tal qual é conhecido, decorre do Direito Romano e regula a sucessão de uma pessoa após sua morte. Basicamente, a sucessão era realizada de forma legítima ( $a b$ intestato), ou seja, não havia manifestação escrita do falecido sobre quem deveria sucedê-lo e, por não haver indicação de preferência sucessória, o estado romano observava outros sistemas reguladores, como as Leis das Tábuas, O Direito Pretoriano, O Direito Imperial e o Direito Justinianeu, para definir quem ou quais pessoas fariam jus ao direito de sucessão (LEONE, 2005).

No direito brasileiro, o processo sucessório está regulamento pela Lei $\mathrm{n}^{\circ} 10.406$ de 10 de janeiro de 2002, a qual instituiu o Código Civil Brasileiro, estabelecendo o conjunto de condições e normas para a transferência do patrimônio aos herdeiros, sendo adotados os modelos de sucessão legítima e de sucessão testamentária (BRASIL, 2002).

Destaca-se que, apesar de existirem regras gerais, o modelo de processos sucessórios nas empresas familiares não é único e depende da configuração de cada empresa. O processo de sucessão implica na mudança do tomador de decisão e é um dos principais geradores de tensões nas empresas familiares. Assim, sucedido(s) e sucessor(es) deve(m) estar preparado(s) para lidar com todos os sentimentos e angústias inerentes ao processo sucessório. Ao sucessor cabe ainda o dever de conquistar posição de liderança, uma vez que essa não pode ser transferida de maneira formal (LEONE, 2005).

Oliveira (2006) destaca dois modelos de processo sucessório: i) a sucessão profissional e ii) a sucessão familiar. A primeira implica na contratação de um gestor profissional ao qual será transferido o poder de decisão para mitigar divergências entre propriedade e gestão. Nesse modelo, os membros da família atuam por meio de um conselho e podem ou não interferir na administração do negócio. A segunda ocorre quando uma geração abre espaço para que a outra assuma o controle dos negócios, sendo esse o modelo mais adotado entre as empresas familiares. 
Entretanto, para que a sucessão ocorra com relativo sucesso e, consequentemente, para que a empresa familiar aumente suas chances de sobrevivência após a sucessão, é preciso que haja um planejamento sucessório. Dessa forma, Mamede e Mamede (2017) afirmam que não considerar a necessidade de preparar a sucessão constitui uma falha recorrente, além de ser bastante oneroso às empresas. Ainda para os autores, mudanças repentinas de comando podem gerar efeitos negativos e comprometer a sobrevivência das organizações.

Um processo de sucessão premeditado deve considerar a inclusão dos possíveis sucessores na estrutura no tempo devido, visto que, assim, esses poderão vivenciar a empresa na prática e desenvolverão as competências necessárias. Ao contrário, eles também podem ser preparados para ocupar apenas posição de sócios atuantes, mas que delegam a responsabilidade de gestão das operações a um gestor profissional. Inclui-se, ainda, a necessidade de definição sobre a configuração empresarial que melhor atenderá ao processo sucessório e a busca por apoio de profissionais experientes e competentes (OLIVEIRA, 2006).

\subsection{CARGA TRIBUTÁRIA BRASILEIRA}

A elevada carga tributária no Brasil causa impactos na vida das empresas e das pessoas físicas (LIMA; REZENDE, 2019). Em matéria tributária, as empresas rurais brasileiras não fogem à regra e estão obrigadas a cumprirem normas, porém a velocidade e o volume em que são editadas e postas em prática acabam por dificultar a sua compreensão e correta aplicação (MANEIRA; GREGÓRIO JÚNIOR, 2018). Segundo Crepaldi (2012), o custo tributário para produtores rurais pessoa física e pessoa jurídica no mercado interno pode chegar a $32,5 \%$ e $48,8 \%$, respectivamente. Para empresas agroindustriais, o custo tributário pode alcançar 51,9\% no mercado interno e $42,65 \%$ no mercado externo.

Observa-se, porém, alguns esforços das fazendas federal e estadual no sentido de reduzir os impactos tributários sobre a produção agrícola, sobretudo, em relação aos produtos destinados à exportação e àqueles que compõem a cesta básica, conforme ordenamento dado pelo Art. 459, Parte I Anexo IX do RICMS/02, e pelo Artigo 75, Inciso $2^{\circ}$ do Decreto 46.238 de Maio de 2003 (PAULSEM, 2012). Ressalta-se que os esforços mencionados não constituem uma vantagem ao segmento do agronegócio. Dados do Cocafé (2016) apontam que o agronegócio foi o principal contrapeso da balança comercial brasileira. Portanto, a redução dos impactos tributários sobre o agronegócio, em última análise, corresponde a zelar de uma das mais importantes fontes receitas do país.

No Brasil, a tributação é realizada de forma direta (tributos que incidem sobre a riqueza produzida e que são cobrados conforme a capacidade contributiva) e indireta (tributos que são incorporados ao preço de venda do produto). Dentre os tributos diretos, destacam-se Imposto de Renda (IR) e Contribuição Social Sobre o Lucro Líquido (CSLL) (CREPALDI, 2012).

Crepaldi (2012) cita como tributos indiretos os seguintes: Imposto sobre Produtos Industrializados (IPI), Contribuição para o Programa de Integração Social (PIS), Contribuição para a Formação do Patrimônio do Servidor Público (PASEP), Contribuição para o Financiamento da Seguridade Social (COFINS) e Imposto sobre a Circulação de Mercadorias e Serviços (ICMS). Somam-se aos listados as contribuições para: Instituto Nacional do Seguro Social (INSS), Risco Ambiental do Trabalho (RAT), Fundo de Amparo ao Trabalhador (FAT), Serviço Nacional de Aprendizagem Rural (SENAR) e Imposto Sobre Serviços de Qualquer Natureza (ISSQN). Não incidentes sobre a atividade, mas sobre a transmissão patrimonial, acrescentam-se o Imposto Sobre Transmissão Causa Mortis e Doação (ITCM) e o Imposto Sobre a Transmissão de Bens Intervivos (ITBI). Outro ponto importante em relação aos 
tributos, mais especificamente, sobre a folha de pagamento, é a sua desoneração, pois o setor de agronegócio está entre um dos contemplados.

\subsection{PLANEJAMENTO TRIBUTÁRIO}

O termo planejamento designa o ato de buscar determinar a condição e/ou situação desejada. O planejamento deve se constituir no ato primeiro e mais importante de qualquer organização que deseje obter algum sucesso. Nesse sentido, as atividades administrativas de coordenação e controle são facilitadas, uma vez que o objetivo e os meios para alcançá-lo estão claramente determinados (OLIVEIRA et al., 2015).

O planejamento tributário consiste na utilização de mecanismos legais para reduzir os impactos tributários sobre as organizações. Assim, um assunto recorrente nas empresas em todo o país é a elisão fiscal e, legalmente, não há nenhum impeditivo que restrinja o direito do empreendedor de analisar seu negócio e escolher, dentre as possibilidades, aquela que lhe traga maior redução de custos, inclusive, de caráter tributário. No entanto, tal opção requer um profundo conhecimento do negócio e da legislação para não se incorrer na escolha de uma alternativa equivocada ou mesmo na prática do crime de evasão de divisas.

Além do pagamento dos tributos, os contribuintes têm uma série de declarações a entregar ao fisco, bem como precisam atentar para a previsão legal de retenção, necessitam de profissionais adequados para cálculo dos tributos corretamente, sendo essas algumas das atividades que necessitam de gastos para acontecerem de forma satisfatória no que tange às obrigações tributárias (MIYOSHI; NAKAO, 2012). Na visão de Sandford, Godwin e Hardwick (1989), o custo de conformidade é o gasto empreendido para que ocorram os processos tributários da forma mais adjacente da realidade e do solicitado pela legislação.

Inúmeras empresas adotam mecanismos tributários errôneos, resultando tal prática na falta de compreensão da legislação fiscal (MAMEDE; MAMEDE, 2017). O volume de leis e instruções normativas editadas pelo estado brasileiro dificulta a compreensão e a aplicação das normas, levando, em alguns casos, ao descumprimento de obrigações acessórias que resultam em autuações e multas (OLIVEIRA et al., 2015; PEREIRA; TEIXEIRA; GURGEL, 2014). O planejamento tributário permite construir uma cultura empresarial que consolida a postura fiscal por meio de procedimentos uniformes, bem como possibilita o aproveitamento de oportunidades fiscais, evita o recolhimento indevido de tributos, facilita o correto aproveitamento de créditos e, em casos de identificação de recolhimento a menor, promove rapidamente a solução da questão mediante denúncia espontânea e do recolhimento da diferença (MAMEDE; MAMEDE, 2017).

Destaca-se ainda que a solução criada para um exercício pode não atender aos demais, exigindo atualizações constantes da tecnologia fiscal e jurídica frente às mudanças legislativas. Sobre esse aspecto, Borges (2006) e Fabretti (2016) ressaltam que o especialista em planejamento tributário deve providenciar, sistematicamente, verificações para obtenção da excelência nos resultados de seu trabalho.

\subsection{HOLDING}

Holding é o termo inglês utilizado para qualificar as sociedades empresariais que têm como objetivo exercer o controle patrimonial e acionário sobre outras empresas, possibilitando a consolidação do processo de gestão, centralizando as decisões e fazendo prevalecer a força econômica de um grupo empresarial. Entretanto, não é correto afirmar que esse seja o único objetivo de uma holding, podendo ela também praticar atividades operacionais (SILVA; 
ROSSI, 2017). No Brasil, tal configuração empresarial está regulamentada pela Lei n. 6.404/76 - Lei das Sociedades Anônimas.

Também é comum ouvir falar em holdings familiares, que são aquelas constituídas, principalmente, com o objetivo de facilitar o planejamento societário. A constituição de uma holding familiar possibilita a separação das áreas operacionais de áreas puramente patrimoniais. Além disso, elas representam a configuração societária adequada para guardar e gerir o controle acionário sobre outras organizações. Conforme as particularidades das atividades empresariais, torna-se possível, por meio de uma holding, centralizar as decisões mais importantes e, ao mesmo tempo, distribuir as atividades operacionais, alcançando benefícios jurídicos e reduzindo custos e riscos (SILVA; ROSSI, 2017; MAMEME; MAMEDE, 2017). Mamede e Mamede (2017) apontam que o planejamento societário mediante a holding é uma forma de realizar uma reconfiguração organizacional, garantindo o funcionamento eficiente e seguro da corporação, incluindo intervenções em processos, nas atividades e no patrimônio.

Os tipos mais comuns de holdings são a pura e a mista. A primeira é constituída com a finalidade exclusiva de exercer o controle acionário e patrimonial sobre outras empresas por meio da titularidade de suas cotas e/ou ações (SILVA; ROSSI, 2017). Já a segunda contempla tanto o objetivo da primeira quanto o de exercer alguma atividade produtiva que pode ser específica ou complementar à atividade exercida por uma de suas controladas (SILVA; ROSSI, 2017). Além dos tipos aqui mencionados, é comum encontrar os termos holding de controle, holding de participação, holding de administração, holding de organização, holding patrimonial e holding imobiliária (SILVA; ROSSI, 2017).

Retornando ao termo holding familiar, destaca-se que não se trata de uma tipologia específica, mas de uma contextualização, podendo tal sociedade ser constituída como holding pura ou mista. Quanto à natureza jurídica, Mamede e Mamede (2017) afirmam que as holdings podem ser constituídas nas formas de sociedades limitadas ou de sociedades anônimas, esclarecendo também que não há vedação jurídica quanto ao limite ou tipo de pessoa que pode participar das sociedades holdings, ou seja, se pessoa jurídica ou pessoa física, ou mesmo quanto ao tipo societário.

\section{ASPECTOS METODOLÓGIOCOS}

Quanto à sua natureza, esta é uma pesquisa aplicada, pois visa solucionar um problema real do grupo empresário que é a escolha do melhor regime tributário, inclusive, com a possibilidade do uso de holding para auxiliar no processo sucessório. Em relação à abordagem, esta pesquisa caracteriza-se como qualitativa devido à não utilização de dados estatísticos para apresentação dos resultados. Quanto aos objetivos metodológicos, é descritivo, haja vista a descrição dos resultados com base nos dados coletados. Em relação aos procedimentos bibliográfico e documental, destaca-se que o primeiro ocorre mediante uso de materiais já disponíveis em livros e artigos e o segundo ocorre com a coleta dos documentos gerenciais compostos pelas projeções dos orçamentos da organização referente aos períodos de 2016 a 2019 (realizado) e de 2020 a 2022 (orçado). Os dados foram cedidos pela empresa por meio de seu departamento financeiro no formato de documento eletrônico.

Os dados foram tratados e padronizados mediante o uso de planilhas eletrônicas para garantir sua uniformidade e facilitar o processo de análise. Ressalta-se que o estudo foi desenvolvido no empreendimento de um grupo de agricultores familiares do estado de Minas Gerais atuantes como produtores rurais pessoa física. A empresa tem três sócios, sendo um médico, uma dentista e uma advogada. 
Cumprida a etapa de padronização, os dados referentes ao orçamento foram convertidos no modelo de Demonstração de Resultados do Exercício (DRE) para o cálculo do resultado líquido e a tributação referente a cada exercício. Em cada exercício, foram calculados os resultados nas modalidades tributárias de Pessoa Física (com base no livro caixa e com base na presunção da receita), Pessoa Jurídica (Lucro Real, Lucro Presumido e Simples Nacional), além da Combinação de Pessoal Física e Pessoa Jurídica no Lucro Real e no Lucro Presumido. Destaca-se que, para os cálculos do Lucro Real, foram consideradas as adições e as exclusões necessárias, conforme dispõe a legislação atual. Por fim realizou o cálculo da taxa efetiva de cada regime tributário.

\section{ANÁLISE E DISCUSSÃo DOS RESULTADOS}

Conforme proposto, utilizou-se da fundamentação teórica e de técnicas contábeis e tributária para encontrar a solução mais adequada ao problema pesquisado. As análises de ordem tributária compreenderam o período de 2016 a 2022 e foram realizadas como base nas informações coletadas nos orçamentos fornecidos pelo grupo empresarial, não desprezando ajustes conforme legislação tributária brasileira. Ainda em acordo com a proposta inicial, os dados do orçamento foram convertidos no modelo de Demonstração de Resultado do Exercício (DRE), aplicando-se, para cada ano, os modelos de tributação pelo Lucro Real, Lucro Presumido e Simples Nacional (pessoa jurídica), bem como os modelos operacionais da pessoa física (com base no livro caixa e receita presumida) e holding com operação mista.

Para acompanhar a evolução do arcabouço tributário, a partir de abril do ano de 2018, a alíquota do Funrural foi alterada para 1,5\% (pessoa física) e 2,05\% (pessoa jurídica), visto que, no período anterior, eram, respectivamente, de $2,3 \%$ e $2,85 \%$, permanecendo inalterados os orçamentos disponibilizados pela empresa. Destaca-se que, em todos os anos, foi considerado o Funrural sobre o faturamento, pois esse gera menor desembolso para o grupo, em relação ao Funrural, para cobertura da folha de pagamento.

Nas situações em que foram consideradas as possibilidades de operações conjuntas (holding - Pessoal Física e Pessoa Jurídica no Lucro Real e no Lucro Presumido holding), houve aumento no valor das despesas das pessoas físicas com pagamento de aluguel dos imóveis explorados, bem como aumento nas receitas da pessoa jurídica com o recebimento de aluguéis dos imóveis cedidos às pessoas físicas.

O processo sucessório encontra-se regulamentado no direito brasileiro desde 2002, quando foi publicada a Lei n ${ }^{\circ} 10.406$ que instituiu o Código Civil Brasileiro. Desde então, há um conjunto de condições e normas para a transferência do patrimônio aos herdeiros, sendo adotados os modelos de sucessão legítima e de sucessão testamentária (BRASIL, 2002). Leone (2005) afirma que, mesmo com a existência de regras gerais, o processo sucessório depende da configuração de cada organização, sendo a sucessão um dos principais geradores de tensão nas empresas.

Conforme Silva e Rossi (2017), as sociedades empresariais do tipo holding objetivam a cessão do controle patrimonial e acionário sobre outras companhias, bem como a participação nas atividades operacionais. Para Mamede e Mamede (2017), a holding possibilita a separação das áreas operacionais de áreas puramente patrimoniais. Os autores ressaltam ainda a existência da holding familiar com vistas a facilitar o planejamento societário e sucessório, representando uma configuração adequada para guardar e gerir o controle acionário nas organizações.

Em sequência, nas Tabelas 1 a 4, são apresentados, respectivamente, os seguintes tópicos: i) resultado do grupo econômico; ii) desembolso com tributos sobre o lucro; iii) desembolso com tributos sobre a folha de pagamento; e iv) alíquota efetiva. 
O resultado econômico é composto pelo confronto das receitas e despesas da empresa em cada ano. O lucro foi considerado como um ponto importante na escolha do regime tributário, pois, segundo Graham et al. (2013), o lucro tem prioridade sobre os tributos pagos, pois esse pode impactar outras decisões dos gestores.

Os tributos sobre o lucro considerados foram o Documento de Arrecadação do Simples Nacional (DAS) para o Simples Nacional; para os regimes livro-caixa e regime presumido nas operações como Pessoa Física foi o Imposto de Renda Pessoa Física e para o Lucro Real e Presumido foram Imposto de Renda Pessoa Jurídica. No caso das holdings, houve a divisão das receitas e despesas em quatro partes iguais, tendo a tributação incidência para pessoa física, considerando os três sócios e para a empresa, conforme legislação. A empresa também tinha receitas financeiras que foram tributadas pelo PIS e COFINS em 4,65\% no Lucro Real. Em relação aos tributos sobre a folha de pagamento, foram considerados o Fundo de Garantia por Tempo de Serviço (FGTS) e o Funrural sobre faturamento. A alíquota efetiva foi calculada mediante a soma dos tributos sobre o lucro e a folha de pagamento dividida pela soma das receitas totais do grupo. A empresa não é tributada pelo ICMS, pois a sua produção é para exportação, detendo, assim, a imunidade tributária.

Tabela 1 - Ranking de resultado do grupo econômico por configuração societária e modelo tributário

\begin{tabular}{|c|c|c|c|c|c|c|c|}
\hline & \multicolumn{2}{|c|}{ PESSOA FÍSICA } & \multicolumn{2}{|c|}{ PESSOA JURÍDICA } & \multicolumn{2}{|c|}{ HOLDING } & \multirow{2}{*}{$\begin{array}{c}\text { SIMPLES } \\
\text { NACIONAL }\end{array}$} \\
\hline & $\begin{array}{c}\text { LUCRO } \\
\text { REAL }\end{array}$ & $\begin{array}{c}\text { LUCRO } \\
\text { PRESUMIDO }\end{array}$ & $\begin{array}{l}\text { LUCRO } \\
\text { REAL }\end{array}$ & $\begin{array}{c}\text { LUCRO } \\
\text { PRESUMIDO }\end{array}$ & $\begin{array}{l}\text { LUCRO } \\
\text { REAL }\end{array}$ & $\begin{array}{c}\text { LUCRO } \\
\text { PRESUMIDO }\end{array}$ & \\
\hline 2016 & $789.460,59$ & 669.79 & $695.957,52$ & $812.437,47$ & $795.409,36$ & $721.507,88$ & 5,14 \\
\hline 2017 & 203.267,27 & $-131.896,96$ & 160.132 & 8.8 & 130.5 & -81.4 & 7,05 \\
\hline 2018 & 187.7 & -187 & 13 & -3 & 0 & -13 & 3 \\
\hline 2019 & 445.260 & $86.340,98$ & 374.791 & 264.9 & 448 & $158.764,61$ & 8,53 \\
\hline 2020 & 3 & -520 & -1 & -288 & $-c$ & -3 & -4 \\
\hline 2021 & $842.001,18$ & $504.048,40$ & $720.526,48$ & $742.755,37$ & $824.146,32$ & $-308.978,80$ & $124.648,53$ \\
\hline 2022 & $129.000,12$ & $-486.361,88$ & $05.150,85$ & -230. & $95.396,54$ & $-308.978,80$ & $-327.011,10$ \\
\hline TOTAL & $2.634 .742,43$ & $-66.155,29$ & $2.140 .848,92$ & $1.269 .493,11$ & $2.340 .300,23$ & $-347.540,41$ & $-232.513,99$ \\
\hline
\end{tabular}

Fonte: Elaborada pelos autores

Tabela 2 - Ranking de desembolso dos tributos sobre o lucro do grupo econômico por configuração societária e modelo tributário

\begin{tabular}{|c|c|c|c|c|c|c|c|}
\hline & \multicolumn{2}{|c|}{ PESSOA FÍSICA } & \multicolumn{2}{|c|}{ PESSOA JURÍDICA } & \multicolumn{2}{|c|}{ HOLDING } & \multirow{2}{*}{$\begin{array}{l}\text { SIMPLES } \\
\text { NACIONAL }\end{array}$} \\
\hline & $\begin{array}{c}\text { LUCRO } \\
\text { REAL }\end{array}$ & $\begin{array}{c}\text { LUCRO } \\
\text { PRESUMIDO } \\
\end{array}$ & $\begin{array}{l}\text { LUCRO } \\
\text { REAL }\end{array}$ & $\begin{array}{c}\text { LUCRO } \\
\text { PRESUMIDO } \\
\end{array}$ & $\begin{array}{l}\text { LUCRO } \\
\text { REAL }\end{array}$ & $\begin{array}{c}\text { LUCRO } \\
\text { PRESUMIDO } \\
\end{array}$ & \\
\hline 2016 & $-266.822,79$ & $-386.487,68$ & $-322.159,93$ & $-205.679,98$ & $-257.222,27$ & $-331.123,75$ & $-332.088,51$ \\
\hline 2017 & $-44.473,60$ & $-379.637,82$ & $-50.568,05$ & -201. & $-113.490,39$ & $-325.579,10$ & 46,78 \\
\hline 2018 & $-38.579,09$ & $-414.202,03$ & $-43.520,03$ & $-221.200,02$ & $-112.163,15$ & $-353.557,26$ & $-322.404,62$ \\
\hline 2019 & $-136.264,03$ & $-495.183,27$ & $-156.710,60$ & $-266.549,51$ & $-129.040,78$ & $-419.107,89$ & $-342.733,47$ \\
\hline 2020 & - & $-558.181,63$ & - & $-275.334,83$ & $-98.917,91$ & $-431.806,67$ & $-357.304,89$ \\
\hline 2021 & $-286.751,97$ & $-624.704,75$ & $-334.816,67$ & $-312.587,78$ & $-300.955,08$ & $-491.321,86$ & $-441.411,17$ \\
\hline 2022 & $-16.314,68$ & $-631.706,68$ & $-20.573,95$ & $-316.508,86$ & $-86.946,51$ & $-491.321,86$ & $-360.161,90$ \\
\hline TOTAL & $-789.206,15$ & $-3.490 .103,87$ & $-928.349,23$ & $-1.799 .705,05$ & $-1.098 .736,09$ & $-2.843 .818,38$ & $-2.487 .051,33$ \\
\hline
\end{tabular}

Fonte: Elaborada pelos autores 
Tabela 3 - Ranking de desembolso dos tributos sobre a folha de pagamento do grupo econômico por configuração societária e modelo tributário

\begin{tabular}{cccccccc}
\hline & \multicolumn{2}{c}{ PESSOA FÍSICA } & \multicolumn{2}{c}{ PESSOA JURÍDICA } & \multicolumn{2}{c}{ HOLDING } & \multirow{2}{*}{ SIMPLES } \\
\cline { 2 - 7 } & LUCRO & LUCRO & LUCRO & LUCRO & LUCRO & LUCRO & NACIONAL \\
& REAL & PRESUMIDO & REAL & PRESUMIDO & REAL & PRESUMIDO & \\
\cline { 2 - 7 } 2016 & $\mathbf{- 1 9 7 . 1 3 2 , 1 5}$ & $\mathbf{- 1 9 7 . 1 3 2 , 1 5}$ & $-235.298,08$ & $-235.298,08$ & $\mathbf{- 1 9 7 . 1 3 2 , 1 5}$ & $\mathbf{- 1 9 7 . 1 3 2 , 1 5}$ & $-235.298,08$ \\
2017 & $\mathbf{- 4 4 0 . 7 7 4 , 0 1}$ & $\mathbf{- 4 4 0 . 7 7 4 , 0 1}$ & $-477.814,68$ & $-477.814,68$ & $\mathbf{- 4 4 0 . 7 7 4 , 0 1}$ & $\mathbf{- 4 4 0 . 7 7 4 , 0 1}$ & $-477.814,68$ \\
2018 & $\mathbf{- 1 5 7 . 8 8 0 , 9 4}$ & $\mathbf{- 1 5 7 . 8 8 0 , 9 4}$ & $-202.853,76$ & $-202.853,76$ & $\mathbf{- 1 5 7 . 8 8 0 , 9 4}$ & $\mathbf{- 1 5 7 . 8 8 0 , 9 4}$ & $-202.853,76$ \\
2019 & $\mathbf{- 1 7 9 . 1 1 6 , 9 7}$ & $\mathbf{- 1 7 9 . 1 1 6 , 9 7}$ & $-229.139,47$ & $-229.139,47$ & $\mathbf{- 1 7 9 . 1 1 6 , 9 7}$ & $\mathbf{- 1 7 9 . 1 1 6 , 9 7}$ & $-229.139,47$ \\
2020 & $\mathbf{- 3 1 4 . 8 2 4 , 2 0}$ & $\mathbf{- 3 1 4 . 8 2 4 , 2 0}$ & $-366.342,70$ & $-366.342,70$ & $\mathbf{- 3 1 4 . 8 2 4 , 2 0}$ & $\mathbf{- 3 1 4 . 8 2 4 , 2 0}$ & $-366.342,70$ \\
2021 & $\mathbf{- 1 9 0 . 6 9 7 , 8 9}$ & $\mathbf{- 1 9 0 . 6 9 7 , 8 9}$ & $-264.107,89$ & $-264.107,89$ & $\mathbf{- 1 9 0 . 6 9 7 , 8 9}$ & $\mathbf{- 1 9 0 . 6 9 7 , 8 9}$ & $-264.107,89$ \\
2022 & $\mathbf{- 2 1 0 . 9 6 9 , 8 1}$ & $\mathbf{- 2 1 0 . 9 6 9 , 8 1}$ & $-270.589,81$ & $-270.589,81$ & $\mathbf{- 2 1 0 . 9 6 9 , 8 1}$ & $\mathbf{- 2 1 0 . 9 6 9 , 8 1}$ & $-270.589,81$ \\
TOTAL & $\mathbf{- 1 . 6 9 1 . 3 9 5 , 9 6}$ & $\mathbf{- 1 . 6 9 1 . 3 9 5 , 9 6}$ & $-2.046 .146,39$ & $-2.046 .146,39$ & $\mathbf{- 1 . 6 9 1 . 3 9 5 , 9 6}$ & $\mathbf{- 1 . 6 9 1 . 3 9 5 , 9 6}$ & $-2.046 .146,39$ \\
\hline
\end{tabular}

Fonte: Elaborada pelos autores

Tabela 4 - Ranking de carga tributária efetiva do grupo econômico por configuração societária e modelo tributário

\begin{tabular}{cccccccc}
\hline & \multicolumn{2}{c}{ PESSOA FISICA } & \multicolumn{2}{c}{ PESSOA JURÍDICA } & \multicolumn{2}{c}{ HOLDING } & SIMPLES \\
\cline { 2 - 7 } & $\begin{array}{c}\text { LUCRO } \\
\text { REAL }\end{array}$ & $\begin{array}{c}\text { LUCRO } \\
\text { PRESUMIDO }\end{array}$ & $\begin{array}{c}\text { LUCRO } \\
\text { REAL }\end{array}$ & $\begin{array}{c}\text { LUCRO } \\
\text { PRESUMIDO }\end{array}$ & $\begin{array}{c}\text { LUCRO } \\
\text { REAL }\end{array}$ & $\begin{array}{c}\text { LUCRO } \\
\text { PRESUMIDO }\end{array}$ & NACIONAL \\
\cline { 2 - 7 } 2016 & $4,77 \%$ & $6,00 \%$ & $5,73 \%$ & $\mathbf{4 , 5 3 \%}$ & $4,67 \%$ & $5,43 \%$ & $5,83 \%$ \\
2017 & $\mathbf{4 , 4 6 \%}$ & $7,54 \%$ & $4,85 \%$ & $6,24 \%$ & $5,09 \%$ & $7,04 \%$ & $7,43 \%$ \\
2018 & $\mathbf{1 , 3 8 \%}$ & $4,01 \%$ & $1,73 \%$ & $2,97 \%$ & $1,89 \%$ & $3,59 \%$ & $3,68 \%$ \\
2019 & $3,11 \%$ & $6,64 \%$ & $3,80 \%$ & $4,88 \%$ & $\mathbf{3 , 0 4 \%}$ & $5,89 \%$ & $5,63 \%$ \\
2020 & $\mathbf{2 , 6 2 \%}$ & $7,26 \%$ & $3,05 \%$ & $5,34 \%$ & $3,44 \%$ & $6,21 \%$ & $6,02 \%$ \\
2021 & $\mathbf{3 , 4 3 \%}$ & $5,85 \%$ & $4,30 \%$ & $4,14 \%$ & $3,53 \%$ & $4,90 \%$ & $5,07 \%$ \\
2022 & $\mathbf{2 , 5 7 \%}$ & $9,51 \%$ & $3,29 \%$ & $6,63 \%$ & $3,36 \%$ & $7,93 \%$ & $7,12 \%$ \\
TOTAL & $\mathbf{3 , 1 9 \%}$ & $6,69 \%$ & $3,82 \%$ & $4,96 \%$ & $3,57 \%$ & $5,85 \%$ & $5,83 \%$ \\
\hline
\end{tabular}

Fonte: Elaborada pelos autores

O exercício social de 2016 apresenta o melhor resultado líquido na configuração de Pessoa Jurídica tributada pelo Lucro Presumido, com carga tributária efetiva em 4,53\%. Entretanto, em 2016, esse grupo foi tributado como Pessoa Física com base no livro-caixa, o que significou um desembolso tributário de $\mathrm{R} \$ 463.954,94$, isto é, poderiam ter sido economizados $\mathrm{R} \$$ 22.976,88.

Para os anos de 2017 e 2018, observou-se uma inversão da situação, visto que os melhores resultados líquidos foram verificados na configuração de Pessoa Física com base no livro-caixa, com carga tributária efetiva ficando em 4,46\% e 1,38\%. Portanto, nesses dois períodos, apesar da inexistência de estudos de planejamento tributário, houve um acerto do grupo econômico.

Em 2019, a menor carga tributária efetiva (3,04\%) é na configuração de holding tributada pelo Lucro Real. Entretanto, a empresa encontra-se no regime tributário de Pessoa Física tributada com base no livro-caixa, o que resultou em uma carga tributária efetiva de $3,11 \%$. Logo, percebe-se que a empresa teve um desembolso tributário de $\mathrm{R} \$ 7.223,25$ a maior e, como se trata de um negócio, deve-se buscar a maximização dos lucros, podendo esse valor ser revertido em distribuição aos sócios e/ou investimento na própria empresa.

O triênio composto pelos anos de 2020, 2021 e 2022 apontaram, novamente, o modelo da Pessoa Física tributada com base no livro-caixa como o mais eficiente, cuja carga tributária 
efetiva é de $2,62 \%, 3,43 \%$ e $2,57 \%$, respectivamente, para os referidos períodos. Ressalta-se que, para esse período, a empresa irá fazer a opção que lhe gere menor desembolso tributário.

De forma geral, o melhor resultado foi obtido na configuração de Pessoa Física tributada pelo livro-caixa em que se constatou um lucro médio acumulado no período de $\mathrm{R} \$$ 2.634.742,43. No mesmo período, o desembolso tributário médio foi de $\mathrm{R} \$ 2.480 .602,12$ e a carga tributária efetiva média foi de $3,19 \%$. O pior resultado para o intervalo analisado foi constatado na configuração de holding tributada pelo Lucro Presumido, que apresentou prejuízo acumulado médio de $\mathrm{R} \$ 347.540,41$. Além disso, o desembolso tributário médio foi de $\mathrm{R} \$$ 2.843.818,38 e a carga tributária efetiva média ficou em 4,96\%.

Apoiado nas configurações empresariais e nos regimes tributários, foi possível estabelecer um Ranking de viabilidade econômica com a seguinte ordem: Pessoa Física tributada pelo regime de caixa, holding tributada pelo Lucro Real, Pessoa Jurídica tributada pelo Lucro Real, Pessoa Jurídica tributada pelo Lucro Presumido. As configurações de Pessoa Física e holding tributadas pelo Lucro Presumido e Pessoa Jurídica tributada pelo Simples Nacional se mostram inviáveis, pois, no período analisado, todas apresentaram resultados acumulados negativos. A diferença percentual entre o melhor e o pior resultado acumulado foi de $858,11 \%$, representando, em termos monetários, o valor $\mathrm{R} \$ 2.982 .282,83$ para o período analisado.

Em relação aos modelos tributários aplicados no estudo, os resultados apontam para a prevalência do Lucro Real em detrimento do Lucro Presumido e do Simples Nacional. Devido às sazonalidades das receitas e despesas, os modelos de Lucro Presumido e Simples Nacional, no caso deste último, sobretudo, após a alteração na forma de apuração da alíquota efetiva inserida pela Lei complementar $n^{\circ} 155$ de 27 de outubro de 2016, mostraram-se desfavoráveis, pois acarretaram recolhimentos elevados, o que impacta negativamente no resultado geral. Contudo, se forem considerados uma análise não econômica e os benefícios apresentados pela constituição da holding para o processo sucessório, a adoção da holding pode ser adotada pelo grupo econômico. Caso essa seja a opção do grupo econômico, a escolha é holding tributada pelo Lucro Real, visto que essa iria gerar menor desembolso tributário e melhor resultado econômico.

\section{CONSIDERAÇÕES FINAIS}

Este trabalho apresentou um estudo desenvolvido no empreendimento de um grupo de agricultores familiares do Estado de Minas Gerais com o objetivo de verificar a viabilidade de constituição de uma holding para facilitar no processo sucessório familiar e no planejamento tributário.

Por meio do aprofundamento bibliográfico, verificou-se que, sob a ótica do processo sucessório, a constituição da empresa do tipo holding pode ser uma boa alternativa. Essa configuração possibilita realizar a segregação entre áreas patrimoniais e operacionais e estabelecer regras complementares à legislação vigente quanto à participação e ao controle acionário.

No que se refere ao planejamento tributário e à busca pela redução da carga tributária com base nos dados fornecidos pelos empresários, verificou-se que a constituição de uma empresa do tipo holding não traria benefícios tributários para os empreendedores. Em contraposição à operação na Pessoa Física, a holding perde rentabilidade devido ao aumento da carga tributária efetiva. Além disso, a tributação pelo Lucro Presumido e pelo Simples Nacional sofre impacto da sazonalidade das receitas e despesas. 
Este estudo contribuiu com os gestores de empreendimentos do agronegócio que, em muitos casos, acabam por arcar com maior carga tributária, além de terem dificuldades no processo sucessório e, conforme a literatura, esse é um ponto que pode levar empresas à falência. $\mathrm{O}$ estudo se limita a um único grupo econômico e, portanto, os resultados não podem ser generalizados para outras empresas. Logo, este estudo pode ser aplicado em outros segmentos, bem como em empresas do mesmo segmento de forma a direcionar para a escolha dos regimes tributários menos onerosos e auxiliar no processo sucessório.

Ressalta-se que as considerações aqui apresentadas não são definitivas e, portanto, é preciso atentar-se para possíveis modificações na regulamentação civil e tributária. Outro ponto importante é a ampliação do horizonte de avaliação, pois, conforme verificado neste estudo, a tecnologia societária e tributária aplicada a um período pode trazer resultados decrescentes e até negativos em períodos seguintes.

\section{REFERÊNCIAS}

ARAÚJO, M. J. Fundamentos do Agronegócio. 4. ed. São Paulo: Atlas, 2013.

BACHA, C. J. C. Economia e Política Agrícola no Brasil. 2. ed. São Paulo: Atlas, 2012.

BERNHOEFT, R. Como criar, manter e sair de uma sociedade familiar (sem brigar). São Paulo: Ed. SENAC, 1996.

BORGES, H. B. Gerência de Impostos: IPI, ICMS, ISS e IR. 6. ed. São Paulo: Atlas, 2007.

BRASIL. Lei n⿳ 10.406, de janeiro de 2002. Institui o código civil. Brasília, 2002.

Disponível em: https://bit.ly/3dDCp3k. Acesso em: 10 jul. 2018.

CALLADO, A. A. C. Agronegócio. 4. ed. São Paulo: Atlas, 2015.

CONFEDERAÇÃO DA AGRICULTURA E PECUÁRIA DO BRASIL. PIB do agronegócio cresce 3,81\% em 2019. Brasília: CNA, 2020.

CONSELHO DOS EXPORTADORES DE CAFÉ DO BRASIL. Relatório Mensal 2016.

Brasil: CECAFÉ, dez. 2016. Disponível em: https://bit.ly/2JgkNfW. Acesso em: 26 out. 2017.

CREPALDI, S. A. Contabilidade Rural: Uma Abordagem Decisorial. 7. ed. São Paulo: Atlas, 2012.

DANTAS, A. T.; SANTOS, A. M. S. P. Formação econômica do Brasil. Rio de Janeiro: Fundação CACIERJ, 2009. Disponível em: https://bit.ly/3dvthh9. Acesso em: 21 mar. 2019.

FABRETTI, L. C. Contabilidade tributária. 16. ed. São Paulo: Atlas, 2016.

FREITAS, E. C.; FREZZA, C. M. M. Gestão e sucessão em empresa familiar. Revista Gestão e Desenvolvimento, Novo Hamburgo, v. 2, n. 1, nov. 2016. DOI: https://doi.org/10.25112/rgd.v2i1.1063. 
GIORDANO, S. R.; REZENDE, C. L. Cadernos universidade do café. São Paulo: PensaFia, 2010.

GRAHAM, J.R. et al. Incentives for tax planning and avoidance: Evidence from the field. The Accounting Review, v. 89, n. 3, p. 991-1023, 2013.

LAMONICA, M. T.; FEIJÓ, C. A. Crescimento e industrialização no Brasil: uma interpretação à luz das propostas de Kaldor. Revista de Economia Política, São Paulo, v. 31, n. 1, p. 118-138, 2011.

LARGHI, N.; ROSSETTO, R. Inovação e planejamento sucessório são fundamentais à sobrevivência de empresas familiares. O Estado de São Paulo, São Paulo, Economia e Negócios. 2017. Disponível em: https://bit.ly/2UzHssO. Acesso em: 17 nov. 2018.

LEONE, N. M. C. P. G. O processo sucessório em empresas familiares: o exemplo dos comerciantes e o processo no Saara. Organ. Soc., Salvador, v. 11, n. 29, p. 149-172, Apr. 2004. DOI: https://doi.org/10.1590/S1984-92302004000100009.

LEONE, N. M. C. P. G. O. Sucessão na Empresa Familiar: preparando as mudanças para garantir a sobrevivência no mercado globalizado. São Paulo: Atlas, 2005.

LIMA, E. M.; REZENDE, A. J. Um estudo sobre a evolução da carga tributária no Brasil: uma análise a partir da Curva de Laffer. Interações (Campo Grande), Campo Grande, v. 20, n. 1, p. 239-255, jan. 2019. DOI: https://doi.org/10.20435/inter.v0i0.1609.

MAMEDE, G. MAMEDE, E. C. Holding Familiar e suas Vantagens: planejamento jurídico e econômico do patrimônio e da sucessão familiar. 9. ed. São Paulo: Atlas, 2017.

MANEIRA, E.; GREGÓRIO JÚNIOR, E. L. Os Limites da reforma tributária para o agronegócio: a imunidade na exportação como garantia do desenvolvimento nacional. In: SACHSIDA, A.; SIMAS, E. E. S. (Org.). Reforma Tributária IPEA-OAB/DF. Rio de Janeiro: IPEA-OAB/DF, 2018, v. 1, p. 109-128.

OLIVEIRA, D. P. R. Empresa Familiar: como fortalecer o empreendimento e otimizar o processo sucessório. 2. ed. São Paulo: Atlas, 2006.

OLIVEIRA, L. M. et al. Manual de Contabilidade tributária. 14. ed. São Paulo: Atlas, 2015.

PAULSEM, L. Direito tributário: constituição e código tributário à luz da doutrina e da jurisprudência. 14. ed. Porto Alegre: Esmafe, 2012.

PEREIRA, M. W. G.; TEIXEIRA, E. C.; GURGEL, A. C. Uma análise da reforma tributária sobre a economia e a competitividade setorial das macrorregiões brasileiras. Revista de Economia, Curitiba, v. 40, n. 3, p. 146-172, set./dez. 2016.

DOI: http://dx.doi.org/10.5380/re.v40i3.33401 
PETRÓ, M.; CASTRO, R. R. S. Análise do processo sucessório em uma empresa familiar: um estudo de caso em uma indústria metalúrgica no Vale do Paranhana no Rio Grande do Sul. Revista de Administração de Empresas Eletrônica- RAEE, n. 3, p. 1-22, 2016.

SANDFORD, C; GODWIN, M., HARDWICK, P. Administrative and Compliance Costs of Taxation. Bath, UK: Fiscal Publications, 1989.

SILVA, F.; ROSSI, A. A. Holding Familiar: visão jurídica do planejamento societário sucessório e tributário. 2. ed. São Paulo: Trevisan, 2017. 